\title{
PENINGKATAN PERPINDAHAN PANAS PADA FAN COIL UNIT (FCU) DENGAN NANOPARTI $\mathrm{Al}_{2} \mathrm{O}_{3}$
}

\author{
Daud S.Anakottapary ${ }^{1)}$, I N Sutarna ${ }^{2)}$, Putu Wijaya Sunu ${ }^{3, *)}$, I Made Rasta ${ }^{4)}$ \\ 1,2,3Jurusan Teknik Mesin, Politeknik Negeri Bali, Bukit Jimbaran, Badung-Bali, 80364 Indonesia \\ *E-mail: wijayasunu@pnb.ac.id
}

\begin{abstract}
Experimental studies on Fan Coil Unit (FCU) were conducted to investigate heat transfer characteristics due to the addition of $\mathrm{Al}_{2} \mathrm{O}_{3}$ nanoparticles. The aims of this study was to reveal the phenomenon of nanofluid particle influences on heat transfer performance indicators. This investigation used tube and fin FCU type with cold fluid is water- $\mathrm{Al}_{2} \mathrm{O}_{3}$ nanofluid and hot fluid is ambient air. The cold fluid volume flow rate is $15 \mathrm{lpm}$ and the hot fluid mass flow rate is $0.48 \mathrm{~kg} / \mathrm{s}$. The concentration of nanoparticles was $0.1 \%$. The ambient air temperature inlet of FCU is $28 \pm 0,5^{\circ} \mathrm{C}$ while the cold fluid temperature entering the FCU is $19 \pm 0,5^{\circ} \mathrm{C}$. In this study the performance parameters on cold fluid with nanoparticles were compared with no nanoparticles. The results showed that the small addition of nanoparticles in cold fluid increased heat transfer in FCU by $9.2 \%$.
\end{abstract}

Keywords: fan coil unit (FCU), nanoparticle, $\mathrm{Al}_{2} \mathrm{O}_{3}$, heat transfer, nanofluid.

\begin{abstract}
Abstrak
Eksperimental studi pada Fan Coil Unit (FCU) dilakukan untuk menginvestigasi karakteristik perpindahan panas akibat penambahan nanopartikel $\mathrm{Al}_{2} \mathrm{O}_{3}$. Tujuan penelitian ini adalah untuk mengungkap fenomena pengaruh nanofluid partikel pada indikator kinerja perpindahan panas. Pada penelitian ini digunakan FCU jenis tube and fin dengan fluida dingin adalah nanofluid $\mathrm{Al}_{2} \mathrm{O}_{3}$ dan fluida panas adalah udara. Laju aliran volume fluida dingin $15 \mathrm{lpm}$ dan laju aliran massa fluida panas sebesar $0,48 \mathrm{~kg} / \mathrm{s}$. Konsentrasi nanopartikel yang digunakan pada penelitian ini adalah $0,1 \%$. Temperatur udara lingkungan masuk FCU adalah $28 \pm 0,5^{\circ} \mathrm{C}$ sedangkan temperatur fluida dingin yang memasuki FCU adalah $19 \pm 0,5^{\circ} \mathrm{C}$. Pada penelitian ini parameter kinerja pada fluida dingin dengan nanopartikel dibandingkan dengan tanpa nanopartikel. Hasil penelitian menunjukan pemakaian nanopartikel pada fluida dingin mampu meningkatkan perpindahan panas pada FCU sebesar $9,2 \%$.
\end{abstract}

Kata Kunci: fan coil unit ( $F C U$ ), nanopartikel , $\mathrm{Al}_{2} \mathrm{O}_{3}$, perpindahan panas, nanofluid.

\section{PENDAHULUAN}

Sistem penyejuk udara (AC) yang merupakan serangkaian proses pengaturan dan pembersihan udara untuk memberikan kenyamanan termal kepada penghuni di dalam ruangan. Disisi lain sistem pengkondisian udara juga menimbulkan dampak negatif pada lingkungan berupa potensi pemanasan global (Purwanto $d k k$, 2006) dan rusaknya lapisan ozon. Emisi gas rumah kaca nasional mencapai 500 juta ton $\mathrm{CO}_{2}$ equivalen pada tahun 2005 dan diprediksi akan mencapai dua kali lipat pada tahun 2025. Atmosfer bumi juga mengalami dampak akibat konsumsi energi listrik untuk industri, rumah tangga maupun dampak langsung akibat kebocoran refrigeran dan pemakaian bahan bakar fosil. Oleh karena itu usaha sekecil apapun dalam upaya peningkatan efisiensi dan konservasi energi sistem pengkondisian udara akan memberikan efek yang signifikan terhadap penurunan konsumsi energi dan dampak lingkungan.

Pasif teknik pada sistem engineering menjadi semakin populer mengingat kemudahaan dalam aplikasi yaitu tanpa energi input. Berbagai jenis teknik pasif dalam meningkatkan optimasi aliran dan perpindahan kalor diantaranya groove (Sunu $d k k$, 2014, 2015a, 2015b, 2016a, 2016b) dan aplikasi nano partikel (Anakottapary $d k k$, 2017). Salah satu usaha untuk meningkatkan efisiensi penggunaan energi pada sistem AC water chiller adalah meningkatkan konduktifitas termal fluida kerja, dalam hal ini adalah chilled water. Konduktifitas termal dari fluida penghantar kalor merupakan salah satu unsur terpenting dalam pengembangan efisiensi energi dalam sistem AC. Salah satu cara untuk meningkatkan konduktifitas termal fluida kerja pada sistem AC water chiller dan menurunkan konsumsi energi serta dampak lingkungan pada industri perhotelan adalah dengan menggunakan nano-fluid 
partikel sebagai media pemindah panas. Nano-fluid partikel dintegrasikan sebagai sistem refrigeran sekunder yaitu air dingin (chilled water) untuk meningkatkan perpindahan panas pada evaporator dan AHU (air handling unit)/ FCU (fan coil unit).

Pada industri perhotelan, fasilitas yang boros energi adalah pengkondisian udara utamanya AC jenis water chiller dan sistem air panas. Kedua sistem ini mengkonsumsi energi hampir $70 \%$ dari total energi hotel sehingga diperlukan usaha unuk meningkatkan efisiensi energi. Selain itu, akan mengurangi biaya operasional dan meningkatkan nilai kompetitif tidak saja industri perhotelan melainkan aplikasi gedung secara keseluruhan.

Pendinginan ruangan melalui AHU akan dioptimalkan oleh nano-fluid partikel (Liu $d k k$, 2011). Untuk memperkuat fenomena aplikasi pada sistem AC water chiller guna mendapatkan prioritas isu strategis, telah dilakukan studi pendahuluan berbagai riset mengenai upaya peningkatan kinerja chilled water diantaranya (Sunu $d k k, 2017 \mathrm{a}$; Sunu $d k k$, 2017b; Sunu dkk 2017c; Rasta\& Sunu, 2017; Eastman $d k k, 2001$; Kumbhara $d k k$, 2017; Jeyakumar $d k k, 2011$; Masuda $d k k, 1993$; Pak $d k k, 1998$; Sidi $d k k, 2005)$. Anandkumar (2015), pada penelitian ini dilakukan test pada chiller dengan water cooled condenser menggunakan nano-fluid $\mathrm{TiO}_{2}$. Air dan $\mathrm{TiO}_{2}$ berfungsi sebagai fluida kerja dengan konsentrasi volume $2 \mathrm{~g} / \mathrm{l}$. Kondensor berjenis double pipe dengan bahan PVC pada pipa bagian luar dan tembaga pada pipa bagian dalam. Hasilnya, peningkatan performance chiller sebanding dengan peningkatan flowrate.
Hamid $d k k$ (2015), penelitian ini berfokus pada Ethylene Glycol (EG) based nano-fluid dengan teknik dilusi dari Titanium Oksida $\left(\mathrm{TiO}_{2}\right)$ dengan volume ratio terhadap Ethylene Glycol 60:40 sampai konsentrasi 1,5\%.Disamping itu adanya fakta bahwa perubahan temperatur lingkungan yang sangat kecil pada negara beriklim tropis seperti Indonesia, maka kebutuhan pendinginan dari AC akan konstan sepanjang tahun. Ini merupakan kondisi yang sangat menguntungkan untuk aplikasi nano-fluid pada sistem water chiller.

Sampai saat ini belum banyak investigasi yang berhubungan dengan performance sistem AC pada FCU dan kemampu-aplikasian nano-fluid partikel. Penelitian ini akan mengkaji secara eksperimental sebuah teknologi efisiensi energi pada sistem AC water chiller dengan aplikasi nano-fluid partikel $\left(\mathrm{Al}_{2} \mathrm{O}_{3}\right)$. Oleh karena itu investigasi ini mengungkap fenomena aplikasi nano-fluid partikel $\left(\mathrm{Al}_{2} \mathrm{O}_{3}\right)$ terhadap performance secara komprehensip mengenai optimasi aliran chilled water dengan untuk sistem Fan Coil Unit (FCU) pada AC jenis Water Chiller.

\section{METODE PENELITIAN}

Investigasi ini dilakukan dengan mengalirkan chilled water dan nano partikel $\left(\mathrm{Al}_{2} \mathrm{O}_{3}\right)$ yang telah didinginkan oleh sistem refrigerasi pada evaporator ke Fan Coil Unit (FCU) menggunakan pompa centrifugal $125 \mathrm{~W}$. Nano partikel yang digunakan adalah $\left(\mathrm{Al}_{2} \mathrm{O}_{3}\right)$ dengan ukuran $<50 \mathrm{~nm}$ dengan konsentrasi $0,1 \%$.

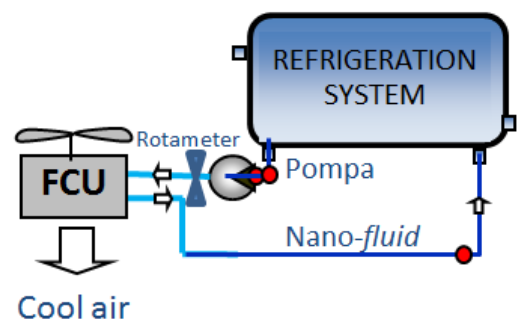

Gambar 1. Simple skema experiment apparatus

Laju aliran chilled water ditahan konstan pada $15 \mathrm{lpm}$, yang diukur menggunakan rotameter jenis in line dengan kapasitas maksimum $18 \mathrm{lpm}$. Chilled water dipompa dari evaporator menuju FCU untuk menyerap kalor udara yang dialirkan melalui FCU oleh blower dengan laju alir massa $0,48 \mathrm{~kg} / \mathrm{s}$. Komponen sistem refrigerasi terdiri atas kompresor, kondensor, alat ekspansi dan evaporator. Secara lebih spesifik, spesifikasi komponen sistem tersaji pada tabel 1.
Tabel 1. Spesifikasi teknis komponen utama sistem Refrigerasi dan FCU Unit

\begin{tabular}{lll}
\hline No & \multicolumn{1}{c}{ Equipment } & \multicolumn{2}{c}{ Description } \\
\hline $\mathbf{1}$ & Compressor & $\begin{array}{l}\text { Hermetically } \\
\text { Rotary 2 pealed, R22 } \\
\text { refrigerant }\end{array}$ \\
\hline $\mathbf{2}$ & Condenser & Air cooled, finned coil. \\
\hline $\mathbf{3}$ & Expansion device & TEV \\
\hline $\mathbf{4}$ & Evaporator (HX) & $\begin{array}{l}\text { Shell and tube heat } \\
\text { exchanger }\end{array}$ \\
\hline $\mathbf{5}$ & Fan coil unit (FCU) & Finned and tube \\
\hline $\mathbf{6}$ & Chilled water pump & Centrifugal, 125 W \\
\hline & Temperatur air dingin masuk/ keluar evaporator \\
dan & temperatur udara masuk/keluar fan coil unit
\end{tabular}


(FCU) diukur menggunakan 4 buah termokopel type K. Signal termokopel didigitalisasi menggunakan data logger dan direkam menggunakan memori komputer selama 900 detik. Eksperiment ini membandingkan kinerja FCU pada $\mathrm{AC}$ water chiller yang menggunakan nanopartikel $\left(\mathrm{Al}_{2} \mathrm{O}_{3}\right)$ dan tanpa menggunakan nanopartikel $\left(\mathrm{Al}_{2} \mathrm{O}_{3}\right)$ berdasarkan parameter kinerja peralatan pemindah kalor.
Pengambilan data awal dilakukan untuk keadaan chilled water tanpa nano partikel (0\% nanopartikel), data ini merupakan data pembanding untuk melihat efektifitas penggunaan nanopartikel dalam sistem tata udara. Gambar 2 mendeskripsikan jumlah kalor yang mampu diserap chilled water pada FCU.

\section{HASIL DAN PEMBAHASAN}

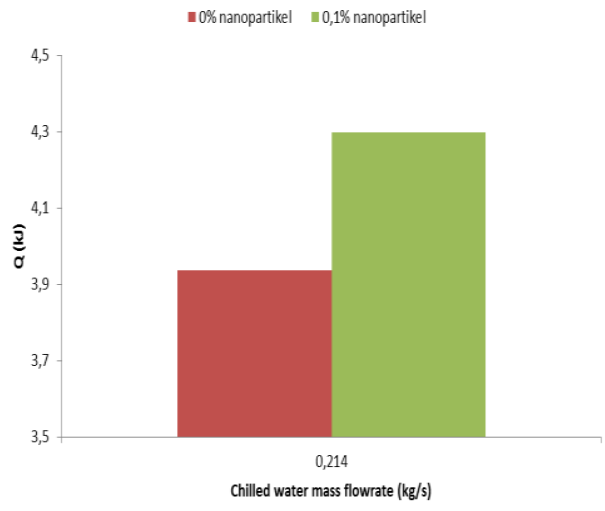

Gambar 2. Perbandingan jumlah kalor diserap chilled water

Terlihat bahwa jumlah kalor yang diserap chilled water dengan nanopartikel sebesar 4,29 kJ, lebih besar dibandingkan dengan chilled water tanpa nanopartikel yang sebesar $3,93 \mathrm{~kJ}$. Konduktifitas panas $(\mathrm{k})$ nano-fluid $\left(\mathrm{Al}_{2} \mathrm{O}_{3}\right)$ pada konsentrasi $1 \%$ dapat mencapai $0.7 \mathrm{~W} / \mathrm{m} \quad \mathrm{K}$ (Liu $d k k$, 2011).
Sedangkan konduktivitas panas chilled water hanya $0.6 \mathrm{~W} / \mathrm{m} \mathrm{K}$. Peningkatan jumlah kalor yang diserap di FCU sebesar 9,2\% diakibatkan karena peningkatan konduktifitas termal chilled water. Fenomena ini juga akan dibuktikan pada gambar 3 .

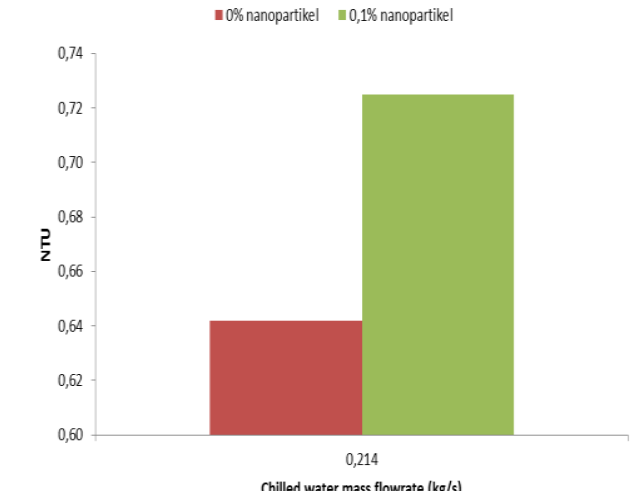

a.

Chilled water mass flowrate $(\mathrm{kg} / \mathrm{s})$

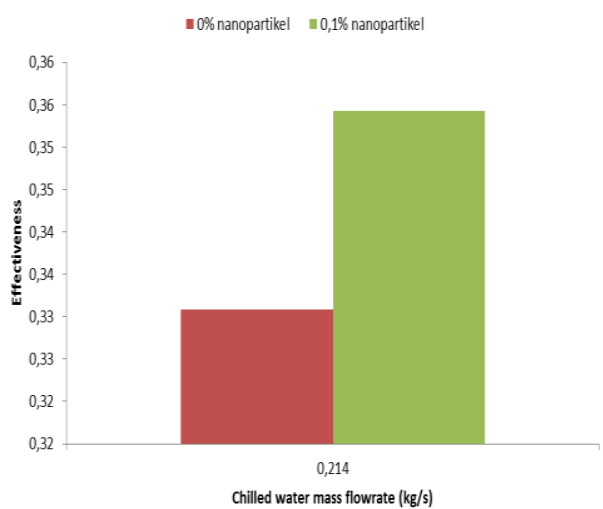

b.

Gambar 3. a.Perbandingan NTU pada FCU; b. Perbandingan effectiveness pada FCU

Gambar 3 memperlihatkan perbandingan nilai Number of Transfer Unit (NTU) dan effectiveness $(\varepsilon)$ dari fan coil unit. Berdasarkan gambar 3, terlihat bahwa penambahan nanopartikel meningkatkan nilai NTU dan effectiveness dari fan coil unit. Peningkatan effectivenes mengindikasikan peningkatan laju perpindahan panas aktual sedangkan peningkatan NTU mendeskripsikan peningkatan nilai koefisien perpindahan panas dan UA value.

\section{SIMPULAN}

Studi experimental pada fan coil unit (FCU) untuk sistem pengkondisian udara jenis water chiller untuk menjelaskan fenomena perpindahan panas akibat penambahan nanopartikel $\left(\mathrm{Al}_{2} \mathrm{O}_{3}\right)$ digunakan analisis NTU dan effectiveness. Dari hasil penelitian ini diperoleh: 
a. Terjadi peningkatan perpindahan panas pada fan coil unit (FCU) sebesar 9,2\% akibat penambahan nanopartikel $\left(\mathrm{Al}_{2} \mathrm{O}_{3}\right) 0,1 \%$.

b. Nilai NTU dan effectiveness meningkat akibat penambahan nanopartikel $\left(\mathrm{Al}_{2} \mathrm{O}_{3}\right)$.

\section{DAFTAR PUSTAKA}

[1] Anakottapary, D.S., Wibolo, A., Sunu, P.W., Rajendra I M. (2017). Approach temperature of heating process in double tube heat exchanger with $\mathrm{Al}_{2} \mathrm{O}_{3}$-water nanofluid. Advanced Science Letters, 23, 12094-12097.

[2] Anandakumar, J. (2015). To conduct the performance test on chiller unit by using nanofluid cooled condenser. International Journal of Mechanical and Robotics Research, 4 (1).

[3] Eastman, J., Choi, S., Li, S., Yu, W., Thompson, L. (2001). Anomalously increased effective thermal conductivities of ethylene glycol-based nanofluids containing copper nanoparticles. Applied Physics Letters, 78, 718-720.

[4] Hamid, K.A., Azmi, W.H., Mamat, R., Usri, N.A., Najafi, G. (2015). Effect of titanium axide nanofluid concentration on pressure drop. ARPN Journal of Engineering and Applied Sciences, 10 (17), 7815-7820.

[5[ Jeyakumar, M., Osama, A., Sumanth, S., Hamed, M. (2011). Heat transfer coefficient and viscosity of alumina-water Nanofluids. 8th International Conference on Heat Transfer, Fluid Mechanics and Thermodynamics.

[6] Kumbhara A., Gulhaneb N., Pandure S. (2017). Effect of various parameters on working condition of chiller. Energy procedia, 109, $479-$ 486

[7] Liu, M. S., Lin, M.C.C., Wang, C. C. (2011). Enhancement of thermal conductivities with $\mathrm{Cu}$, $\mathrm{CuO}$ and carbon nanotube nanofluid and aplication of MWNT/water nanofluid on water chiller system. Nanoscale Research Letters, 6, 297.

[8] Masuda, H., Ebata, A., Teramae, K. and Hishinuma, N. (1993). Alteration of Thermal Conductivity and Viscosity of Liquid by Dispersing Ultra-Fine Particles (Dispersion of Al2O3, SiO2 and TiO2 Ultra-Fine Particles). Netsu Bus-sei (Japan), Vol.7, No. 4, 227-233.

[9] Pak, B.C. and Cho, I.Y. (1998). Hydrodynamic and heat transfer study of dispersed fluids with sub-micron metallic oxide particles. Experimental Heat Transfer, Vol.11, 151-170.
[10] Purwanto, W.W., Nugroho, Y.S., Dalimi, R., Soepardjo, A.H., Wahid, A., Supramono, D, Herminna, D., Adilina, T.A. (2006). Indonesia Energy Outlook and Statistics. Pengkajian Energi Universitas Indonesia, Jakarta.

[11] Rasta, I M.\&Sunu, P. W. (2017). Pengaruh superheat terhadap performansi sistem air conditioning jenis water chiller. Proceeding SNITT-Politeknik Negeri Balikpapan, 288-291.

[12] Sidi, E. B., Palm, S.J., Nguyen, C. T., Roy, G., Galanis, N. (2005). Heat transfer enhancement by using nanofluids in forced convection flows. International Journal of Heat and Fluid Flow 26, 530-546.

[13] Sunu P.W. (2015a) The characteristics of increased pressure drop in pipes with grooves. Adv. Studies Theor. Phys., Vol. 9, no. 2, 57-61.

[14] Sunu P.W., Anakottapary D.S., Santika W.G. (2016a). Temperature approach optimization in the double pipe heat exchanger with groove. Matec web of conference, 58, 04006. doi:10.1051/matecconf/20165804006

[15] Sunu, P. W., Rasta, I M., Anakottapary, D. S., Suarta, I M., Santosa, I D. M. C. (2017b). Capillary tube and thermostatic expansion valve comparative analysis in water chiller air conditioning. IOP Conf. Series: Journal of Physics: Conf. Series, 953, 012063.

[16] Sunu, P. W., Rasta, I M., Anakottapary, D.S. (2017c). Pengaruh panjang pipa kapiler terhadap performance AC jenis water chiller. Proceeding SNITT- Politeknik Negeri Balikpapan, 248-250.

[17] Sunu, P. W., Wardana, I N. G., Sonief A.A, Hamidi, N. (2014). Flow behavior and friction factor in internally grooved pipe wall. $A d v$. Studies Theor. Phys., Vol. 8, no. 14, 643-647.

[18] Sunu, P. W., Wardana, I N. G., Sonief A.A, Hamidi, N. (2015b). The effect of wall groove numbers on pressure drop in pipe flows. Int. J. Fluid Mech. Resch., 42(2), 119 - 130.

[19] Sunu, P. W., Wardana, I N. G., Sonief A.A, Hamidi, N. (2016b). Optimal grooves number for reducing pressure drop. Contemporary Engineering Sciences, Vol. 9, 2016, no. 22, 1067- 1074.

[20] Sunu, P.W., Anakottapary, D.S., Mulawarman, A. A. N. B., Santosa I D. M. C., Negara, I P. S. (2017a). Heat transfer characteristics of Fan Coil Unit (FCU) under the effect of chilled water volume flowrate. IOP Conf. Series: Journal of Physics: Conf. Series, 953012058. 